\title{
Enhanced Fatigue and Durability of Carbon Black/natural rubber Composites Reinforced with Graphene Oxide and Carbon Nanotubes
}

Hao Guo

Beijing University of Chemical Technology

Stephen Jerrams

Technological University Dublin, stephen.jerrams@tudublin.ie

Zongchao Xu

Beijing University of Chemical Technology

See next page for additional authors

Follow this and additional works at: https://arrow.tudublin.ie/cerart

Part of the Polymer and Organic Materials Commons

\section{Recommended Citation}

Guo, H., Jerrams, S., Xu, Z. et al (2020). Enhanced fatigue and durability of carbon black/natural rubber composites reinforced with graphene oxide and carbon nanotubes. Engineering Fracture Mechanics, 223, 106764. doi:10.1016/j.engfracmech.2019.106764

This Article is brought to you for free and open access by the Centre for Elastomer Research at ARROW@TU Dublin. It has been accepted for inclusion in Articles by an authorized administrator of ARROW@TU Dublin. For more information, please contact arrow.admin@tudublin.ie, aisling.coyne@tudublin.ie,gerard.connolly@tudublin.ie.

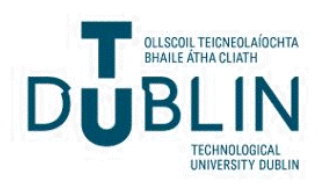


Authors

Hao Guo, Stephen Jerrams, Zongchao Xu, Yanfen Shou, Liang Jiang, Liqun Zhang, Li Liu, and Shipeng Wen

This article is available at ARROW@TU Dublin: https://arrow.tudublin.ie/cerart/19 


\title{
Enhanced fatigue and durability of carbon black/natural rubber composites reinforced with graphene oxide and carbon nanotubes
}

\author{
Hao Guo $^{\mathrm{a}, \mathrm{b}}$, Stephen Jerrams ${ }^{\mathrm{c}}$, Zongchao Xu ${ }^{\mathrm{a}, \mathrm{b}}$, Yanfen Zhou ${ }^{\mathrm{d}}$, Liang Jiang ${ }^{\mathrm{d}}$, \\ Liqun Zhang ${ }^{\mathrm{a}, \mathrm{b}}$, Li Liu ${ }^{\mathrm{a}, \mathrm{b}, *}$, Shipeng Wen ${ }^{\mathrm{a}, \mathrm{b}, *}$ \\ ${ }^{a}$ State Key Laboratory of Chemical Resource Engineering, Beijing University of Chemical Technology, Beijing 100029, China \\ ${ }^{\mathrm{b}}$ Beijing Engineering Research Center of Advanced Elastomers, Beijing University of Chemical Technology, Beijing 100029, China \\ ${ }^{\mathrm{c}}$ Centre for Elastomer Research, Technological University Dublin, Dublin, Ireland \\ ${ }^{\mathrm{d}}$ School of Textile and Garment, Qingdao University, Qingdao 266071, China
}

\section{A R T I C L E I N F O}

\section{Keywords:}

Graphene oxide

Carbon nanotubes

Carbon black

Natural rubber

Fatigue properties

\begin{abstract}
A B S T R A C T
Graphene oxide (GO) sheets and carbon nanotubes (CNTs) are of nanometer size and offer large shape factors which are beneficial in reducing crack propagation rates of composites when used in carbon black (CB) reinforced natural rubber (NR), thereby prolonging the service lives of rubber composites. In this research, CNT-CB/NR and GO-CB/NR composites were prepared by partially replacing $\mathrm{CB}$ with one-dimensional CNTs and two-dimensional flaky graphene oxide GO, respectively. The results showed that the complex filler dispersion in NR matrices was improved due to the isolation effect between the different fillers. The strain-induced crystallization (SIC) ability of CB/NR was effectively enhanced by the addition of both GO and CNT. The modulus at $100 \%$ strain and tear strength of the composites were also improved. More branching and deflections were observed at the crack tips of the composites and both effectively hindered crack propagation in the materials. Under uniaxial and multi-axial cyclic loading, the fatigue lives of CNT-CB/NR and GO-CB/NR composites greatly increased when compared with the fatigue lives of $\mathrm{CB} / \mathrm{NR}$ composites. The GO-CB/NR composites exhibited evident advantages in respect of fatigue resistance and durability among the three composites.
\end{abstract}

\section{Introduction}

Components made of natural rubber (NR) exhibit excellent properties such as high elasticity, wear resistance, flex resistance, durability, etc., due to the material's unique physical and chemical properties. Consequently, NR is widely used in the manufacture of vibration isolators, elastic bearings, tires, seals, gaskets and other products. Compared with synthetic rubbers (SBR, EPDM, IIR, etc.), NR has high tensile strength and excellent fatigue resistance, mainly resulting from its unique ability to undergo strain-induced crystallization (SIC) during stretch $[1,2]$. SIC hinders crack propagation and causes cracks to branch in NR composites, leading to the increases in tearing energy [3].

In order to enhance the fatigue resistance of NR, it is often necessary to introduce nanofillers such as carbon black (CB) [4]. CB can not only enhance the tensile strength, and elastic modulus of NR composites, but also greatly improve durability [5,6]. Stacer et al. [7] found that CB could form a large anisotropic crystalline region at the crack tip and hence give increased strength in the region of

\footnotetext{
*Corresponding authors at: State Key Laboratory of Chemical Resource Engineering, Beijing University of Chemical Technology, Beijing 100029, China.

E-mail addresses: liul@mail.buct.edu.cn (L. Liu), wensp@mail.buct.edu.cn (S. Wen).
} 
high stress concentration region. This decreased the crack propagation rate. Lee et al. [8] also found that CB tended to accumulate in areas of stress concentration in NR and contributed to SIC. SIC effectively dissipated strain energy to improve the fracture resistance of NR. Usually, it is necessary to add high loadings of CB to the NR matrix to obtain excellent mechanical properties and fatigue resistance [9-13]. However, excess CB particles tend to form CB agglomerates due to poor dispersion in processing [14]. In other research, the appearance of stress concentrations and initial cracks were due to CB agglomerates, which decreased the mechanical properties of the NR composites [15]. It is evident that particle shape also has an important influence on the fatigue resistance of the composites. Therefore, new nano-fillers with high aspect ratios were introduced into the CB/NR composite in the research described here in an attempt to increase their fatigue strength.

Recently, graphene (GE) and carbon nanotubes (CNT) have been extensively studied in the field of rubber composite research due to their unique structures and properties [16]. What's more, compared with CB, both CNT and GE have large aspect ratios, which facilitate bridging in the construction of filler networks, disperses stress and reduces crack growth rate[17]. The addition of a small amount of GE or CNT can significantly increase the elastic modulus and stiffness of the composite [18]. However, the mechanical properties of both GE and CNT reinforced nanocomposites would be negatively influenced at high filler contents [19,20], due to the agglomeration and stacking of GE or CNT in the composites. To overcome these issues, CNT bundles of lengths up to $50 \mu \mathrm{m}$ and diameters of 6-8 nm, which were easily dispersed in rubber composite, were chosen in this research [17,21-23]. GO flakes with large specific surface areas and many oxygen-containing groups on their surfaces were chosen [24,25]. This is beneficial for the GO dispersion and formation of a strong interface with a rubber matrix. These features make CNT and GO ideal candidates for retarding crack propagation and improving fatigue resistance of rubber composites.

Therefore, CNT-CB/NR and GO-CB/NR composites were obtained by the introduction of CNT and GO into CB/NR composites in this research. The dispersion state of various fillers, filler networks, the SIC capability, mechanical properties and fatigue behavior under uniaxial and multi-axial cyclic loadings were investigated for these NR based composites.

\section{Experimental}

\subsection{Materials}

NR latex was supplied by the Shanghai Haotai International Trade Co., Ltd., Carbon black (N 330) was supplied by Cabot (China) Co., Ltd. and CNT was obtained from Zhenjiang Tian Nai Technology Co., Ltd. GO was prepared according to the modified Hummers method [26-30]. Other materials used were all commercial reagents.

\subsection{Materials preparation}

Mechanical mixing has been the traditional method for preparing rubber nanocomposites. However, GO was easily aggregated due to the strong Van der Waals forces between GO sheets. If GO had been directly added to NR by mechanical mixing, a poor dispersion of GO would have been achieved. Therefore, the preparation of GO-CB/NR composites included three steps: (1) GO aqueous solution $(2 \mathrm{mg} / \mathrm{ml})$ was prepared by sonication $(800 \mathrm{~W})$ at $50^{\circ} \mathrm{C}$ for $1 \mathrm{~h}$; (2) A calculated amount of GO suspension was then added into the NR latex under intense stirring for $30 \mathrm{~min}$. The GO/NR mixture was then co- coagulated using a $1.0 \mathrm{wt} \%$ calcium chloride solution to obtain the GO/NR masterbatch. The resulting masterbatch was washed with deionized water five times and dried in an oven at $50^{\circ} \mathrm{C}$ for $24 \mathrm{~h}$; (3) $\mathrm{CB}$ and other ingredients were filled into the GO/NR masterbatch by mechanical blending to obtain the GO-CB/NR composites.

CNTs were easily entangled due to their large aspect ratios. Therefore, CNT bundles of lengths up to $50 \mu \mathrm{m}$ and diameters between 6 and $8 \mathrm{~nm}$, which were easily dispersed in rubber composites by mechanical blending, were chosen [21-23]. The CNT bundles were added into prepared $\mathrm{CB} / \mathrm{NR}$ masterbatch to obtain $\mathrm{CNT}-\mathrm{CB} / \mathrm{NR}$ composite by mechanical blending.

Table 1

The formulae of NR composites, $\mathrm{phr}^{\mathrm{a}}$.

\begin{tabular}{|c|c|c|c|c|}
\hline Samples & NR & $\mathrm{CB} / \mathrm{NR}$ & CNT-CB/NR & GO-CB/NR \\
\hline Natural rubber & 100 & 100 & 100 & 100 \\
\hline Zinc oxide & 3.5 & 3.5 & 3.5 & 3.5 \\
\hline Stearic acid & 1 & 1 & 1 & 1 \\
\hline Carbon black (N 330) & - & 40 & 37 & 37 \\
\hline Graphene oxide & - & - & - & 3 \\
\hline Carbon nanotube & - & - & 3 & - \\
\hline Antioxidant $4020^{\mathrm{b}}$ & 2 & 2 & 2 & 2 \\
\hline Antioxidant $\mathrm{RD}^{\mathrm{c}}$ & 2 & 2 & 2 & 2 \\
\hline Accelerator $\mathrm{CZ}^{\mathrm{d}}$ & 2.2 & 2.2 & 2.2 & 2.2 \\
\hline Sulfur & 1.4 & 1.4 & 1.4 & 1.4 \\
\hline
\end{tabular}

a phr: parts by weight per hundred parts of rubber.

b N-1,3-dimethylbutyl-N'-phenyl-p-phenylenediamine.

c Poly (1,2-dihydro-2,2,4-trimethyl-quinoline).

d 2-(4-Morpholinyl dithio) benzothiazole (CBS). 
The CB/NR composites were prepared by mechanical blending according to the formula in Table 1.

\subsection{Characterization}

The dispersion of fillers in the NR matrix was observed by scanning electron microscopy (SEM, S4800, Hitachi, Japan) and transmission electron microscopy (TEM, Tecnai G220, FEI, USA). To obtain a measure of the quality of particle dispersion in the TEM images, the particle analysis was determined using the software Image $\mathrm{J}$ according to our previous research [31]. Also, a dispersion index $D$ was used which reflected particle dispersion in the matrix. The dispersion index $D$ was calculated using the following equation $[31,32]$ :

$$
D=\left(1-\frac{f\left(A_{\mathrm{CB}} / A_{0}\right)}{\Phi_{\mathrm{vol}}}\right) \times 100 \%
$$

where $A_{\mathrm{CB}}$ is the area occupied by $\mathrm{CB}$ agglomerates and the total investigated area is $A_{0}$ which were obtained from the image analysis and are shown in Table S1. The parameter $\Phi_{\mathrm{vol}}$ is the CB volume fraction and $\mathrm{f}$ is a factor related to the density of CB particle and was estimated to be 0.25 [31,32]. Besides the dispersion index, the particle size distribution was also obtained. The filler network was investigated using a rubber processing analyzer (RPA2000, Alpha Technology, USA) at a frequency of $1 \mathrm{~Hz}$ at $60{ }^{\circ} \mathrm{C}$ for a strain range of $0.28 \%$ to $400 \%$. The dynamic mechanical properties of the composites were tested using a dynamic mechanical analyzer (VA3000, Metra VIB, France) under tension at a frequency of $1 \mathrm{~Hz}$ in the range of $-80^{\circ} \mathrm{C}$ to $80^{\circ} \mathrm{C}$ with a heating rate of $3^{\circ} \mathrm{C}$ min ${ }^{-1}$. The mechanical properties were measured by an electronic tensile machine (CMT4104, Xin Sansi, China) according to ISO 37: 2011 and ISO 34-1: 2010 standards. The crystallization degree of NR composites was measured by an X-ray diffractometer (D/max 2500, Rigaku, Japan) using Cu-Ka as the radiation source. The test voltage was $40 \mathrm{kV}$ and the test current was $200 \mathrm{~mA}$. The diffraction angles were scanned from $5^{\circ}$ to $45^{\circ}$ with a scanning speed of $2^{\circ} \mathrm{min}^{-1}$. The crystallinity (CI) of the samples was calculated by the data processing software Jade 6.0 according to equation (2).

$$
C I=\frac{A_{\mathrm{c}}}{A_{\mathrm{c}}+A_{\mathrm{a}}} \times 100 \%
$$

where $A_{\mathrm{c}}$ is the area of the crystal region and $A_{\mathrm{a}}$ is the area of the amorphous region.

The crack propagation rates of the composites were determined by a crack extension analyzer (DMA + 1000, METRA VIB, France) at a frequency of $20 \mathrm{~Hz}$ at $25^{\circ} \mathrm{C}$. The sample size was $2 \mathrm{~mm} \times 6 \mathrm{~mm} \times 40 \mathrm{~mm}$. The pre-cut depth was $1.5 \mathrm{~mm}$ [33]. Under pure shear conditions, the tearing energy of rubber composites can be calculated using the following formula:

$$
G=\frac{E_{\mathrm{f}}}{S}=\frac{E_{\mathrm{f}}}{L \times e}
$$

where $G$ is the tearing energy $\left(\mathrm{J} / \mathrm{m}^{2}\right), E_{\mathrm{f}}$ is the input energy $(\mathrm{J}), S$ is the cross-sectional area of the sample $\left(\mathrm{m}^{2}\right)$, and $L$ and $e$ are the width $(\mathrm{m})$ and thickness $(\mathrm{m})$ of the sample, respectively.

The multi-axial fatigue testing was conducted on a dynamic bubble inflation test system. The test procedures were described in the previous literature $[34,35]$. In this research, the minimum stress was set to $0 \mathrm{MPa}$ and the maximum stress was varied from $5 \mathrm{MPa}$ to $9 \mathrm{MPa}$.

\section{Results and discussion}

\subsection{Filler dispersion}

The fracture surfaces of different rubber composites are shown in Fig. 1. In Fig. 1a, the NR composite without reinforcing fillers showed a smooth fracture surface. In Fig. 1b, numerous dense white spots were attributed to CB particles. In addition, there were many unfilled areas, as indicated by the red circles, which were due to the poor dispersion caused by the CB aggregates. In Fig. $1 \mathrm{c}$ the unfilled areas marked by red circles were significantly reduced indicating that to some extent CNTs were beneficial to the dispersion of CB particles. In Fig. 1d, the unfilled areas marked by red circles were further reduced. This was attributed to GO being interspersed between $\mathrm{CB}$ particles, reducing the degree of agglomeration of the CB particles.

The filler dispersion was further observed by TEM and shown in Fig. 2. In Fig. 2a, the large black particles were considered to be ZnO particles [36]. In Fig. 2b, many distinct black spots identified by the red circles were CB agglomerates. The agglomeration of nanoparticles resulted from spontaneous irreversible behavior causing a reduction in their surface energy. During the fatigue process, these agglomerates tended to induce the initiation points of microcracks which can have the potential to lead to rapid failure of the rubber [37]. In Fig. 2c, numerous thin and lengthy CNTs (marked by red triangles) can be clearly seen. The CNTs were interspersed between the spherical CB particles. In Fig. 2d, GO sheets were also interspersed between the CB particles (marked by red triangles). To further obtain a quantitative evaluation of CB dispersion in different composites, the CB particle size distribution and dispersion index $D$ were as shown in Fig. 3. The statistical size distribution of particles showed that the particles with a size below $100 \mathrm{~nm}$ of CNT-CB/NR and GO-CB/NR composites accounted for $78.0 \%$ and $88.0 \%$ of the total particles respectively, which was higher than that $(64.0 \%)$ of $\mathrm{CB} / \mathrm{NR}$ composites. In addition, the dispersion indices $D$ for the $\mathrm{CB} / \mathrm{NR}$, CNT-CB/NR and GO-CB/NR composites were $68.8 \%, 78.1 \%$ and $85.0 \%$ respectively. The increased small particle distribution and dispersion index indicated that the filler dispersion in CNT-CB/NR and GO-CB/NR matrices became more uniform than that in the CB/NR matrix, due to the addition of CNT and 


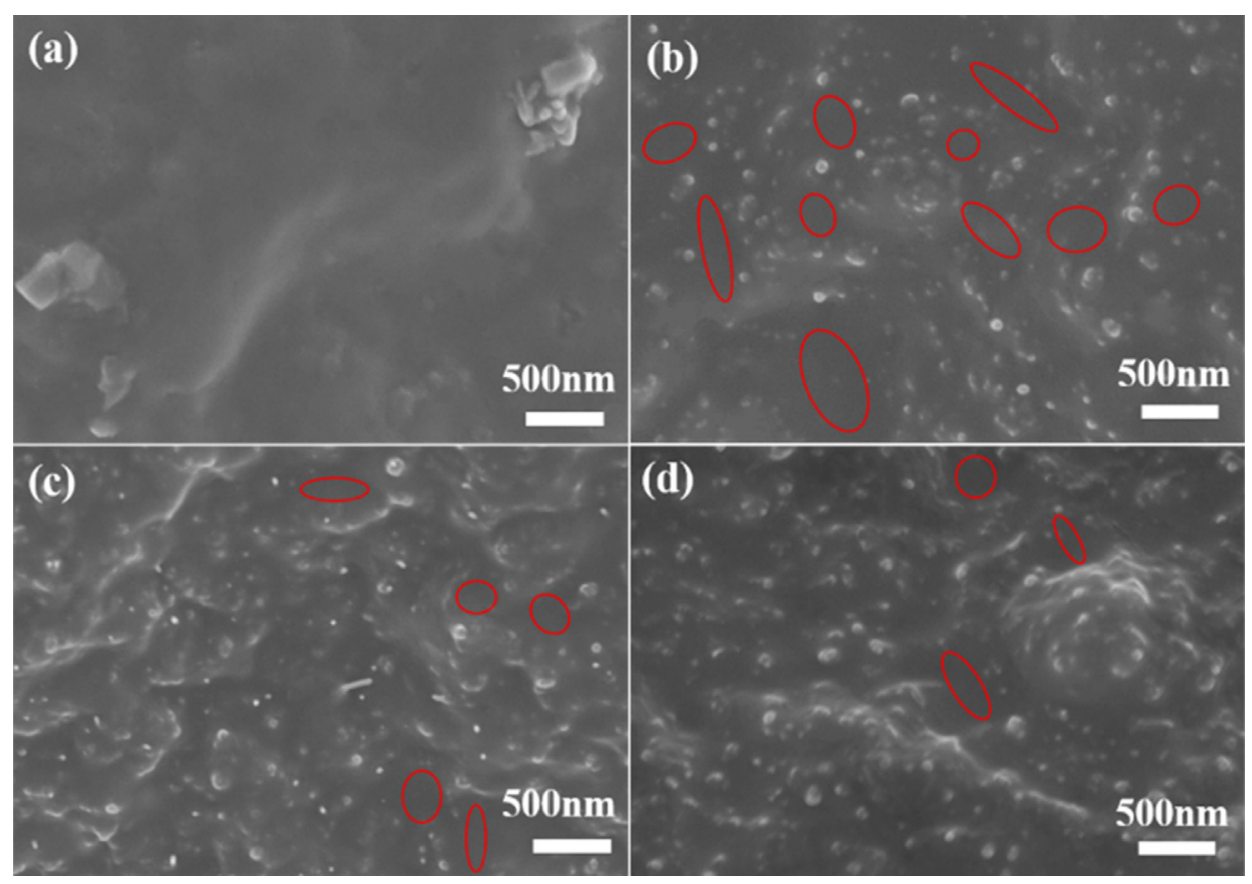

Fig. 1. SEM images of (a) NR (b) CB/NR (c) CNT-CB/NR (d) GO-CB/NR composites.

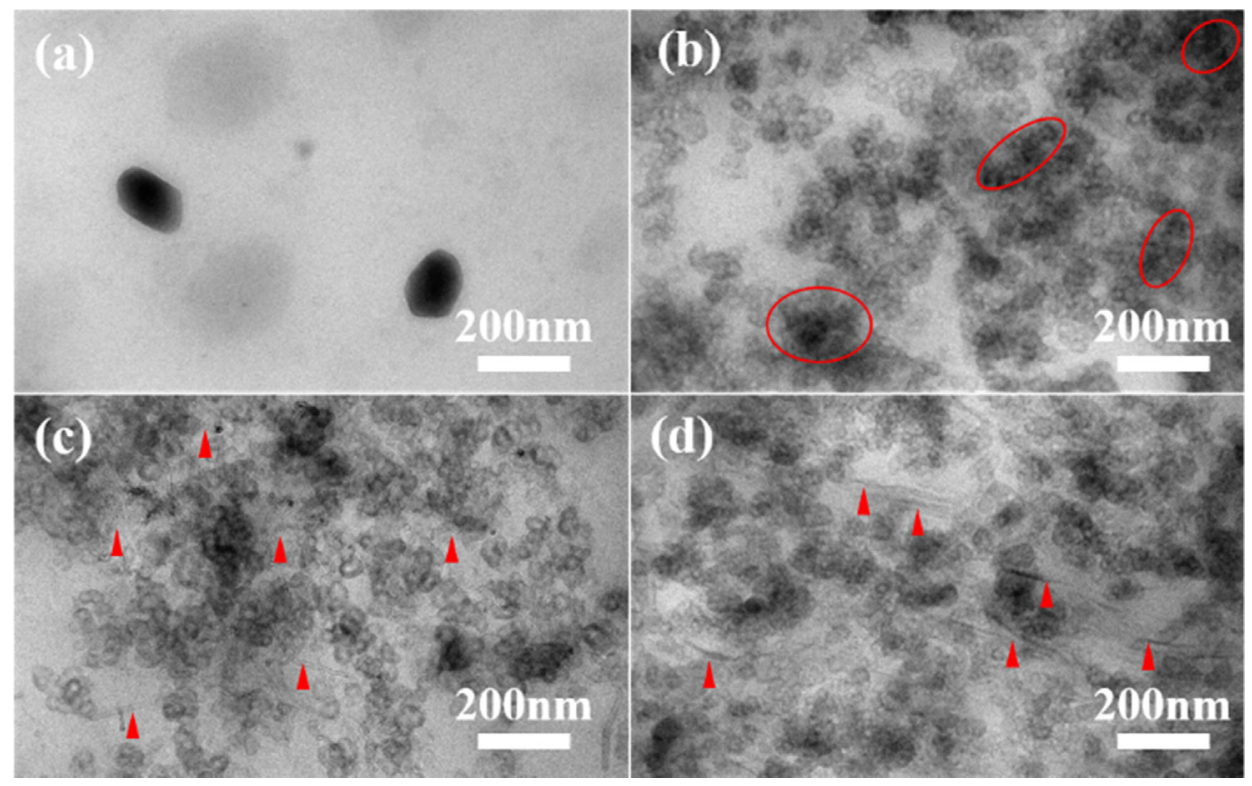

Fig. 2. TEM images of (a) NR (b) CB/NR (c) CNT-CB/NR (d) GO-CB/NR composites.

GO [31].

\subsection{Filler network}

The relationship between the storage modulus and strain reveals the filler network of the composites as shown in Fig. 4a. The typical Payne effect is evident in the behavior of the composites. As strain increased, the storage modulus of the composites rapidly decreased as the initial filler network broke down. Compared with CB/NR composites, the initial storage modulus observed in CNT$\mathrm{CB} / \mathrm{NR}$ and GO-CB/NR composites were significantly higher due to the sheet structure of GO and the larger aspect ratio of CNT. The combination of GO (or CNT) interspersed with the rubber molecular chains formed more rigid networks and hence improved strength. 


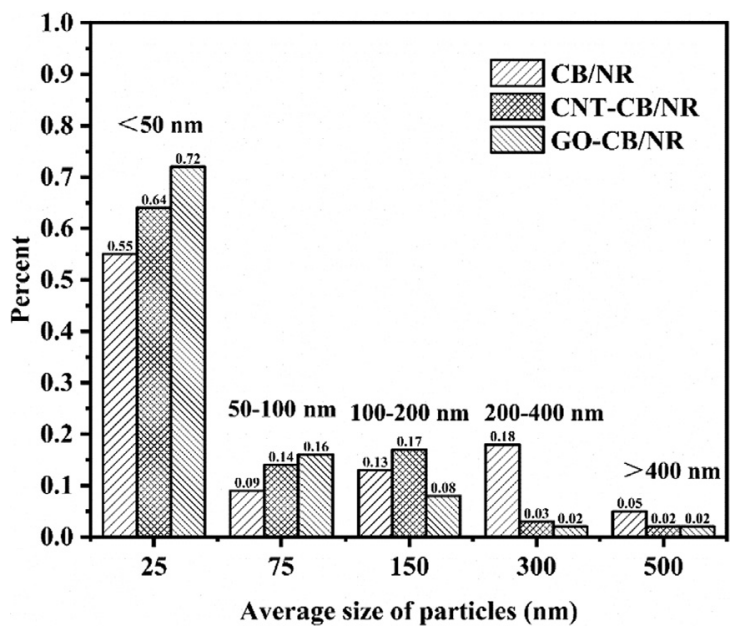

Fig. 3. Statistic size distribution of particles in different composites.
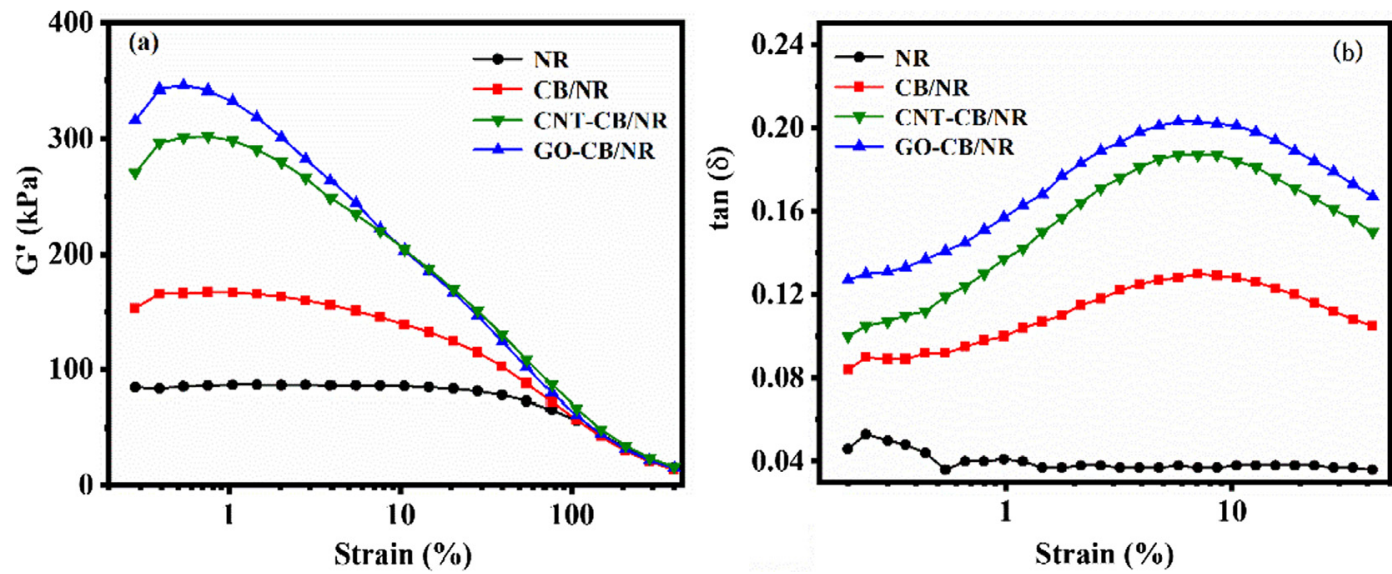

Fig. 4. Storage modulus $\mathrm{G}^{\prime}$ (a) and loss factor $\tan \delta$ (b) versus strain for different NR composites.

Loss factor can be used to reveal the internal friction in a composite. As shown in Fig. 4b, the loss factor first increased and then decreased with increased strain. The loss factors of CB/NR composites were significantly lower than those for CNT-CB/NR and GO$\mathrm{CB} / \mathrm{NR}$ composites, indicating that the viscous losses of GO-CB/NR and CNT-CB/NR composites were larger than for CB/NR composites. This was principally because the both the GO and CNT formed a rigid network with $\mathrm{CB}$ in the NR matrix. The large viscous losses of the CNT-CB/NR and GO-CB/NR composites were beneficial for dissipating energy at the crack tips, thereby delaying crack propagation and prolonging fatigue lives for the reinforced composites.

\subsection{Dynamic mechanical analysis}

To further characterize the interaction between the fillers and the rubber molecules, the dynamic mechanical behavior was determined and comparisons of the three composites are shown in Fig. 5. The temperatures corresponding to the apex of the tan $\delta /$ temperature curves of CNT-CB/NR and GO-CB/NR composites were higher than for the CB/NR composite. Also, the peak values of the loss factors decreased significantly by comparison with $\mathrm{CB} / \mathrm{NR}$. These showed that both GO and CNT provided heightened constraints to the rubber molecular chains, limiting the movement of the rubber molecule chains. The strong interfacial interaction led to greater friction between fillers and rubber molecules and an increase in hysteresis. The higher hysteresis was beneficial to the fatigue resistance of the composites.

\subsection{Mechanical properties}

The mechanical properties of different NR composites are shown in Fig. 6 and Table 2. The modulus of CNT-CB/NR and GO-CB/ $\mathrm{NR}$ at $100 \%$ and $300 \%$ strain are higher than those of the $\mathrm{CB} / \mathrm{NR}$ composite. The tensile strength of CNT-CB/NR and GO-CB/NR increased by $3.4 \%$ and $13.4 \%$, respectively, compared with that of the $\mathrm{CB} / \mathrm{NR}$ composite. This improvement can be attributed to the stable filler network achieved using both CNT and GO with CB in the rubber matrix and the strong interaction between both CNT and 


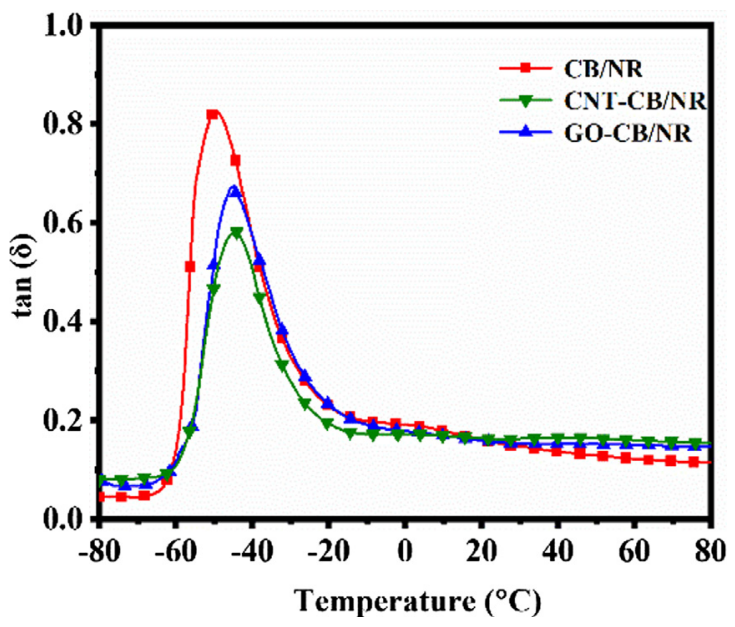

Fig. 5. Loss factor $(\tan \delta$ ) versus temperature of different NR composites.

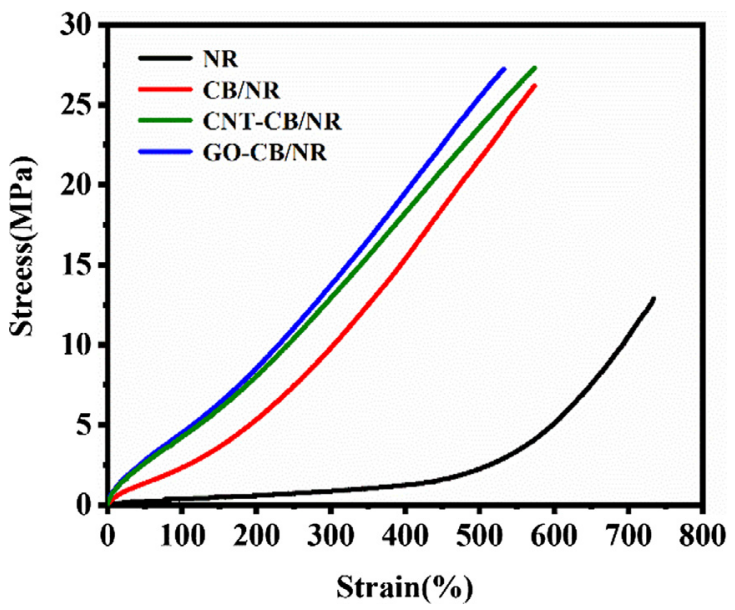

Fig. 6. Stress-strain curves of NR composites.

Table 2

Mechanical properties of NR composites.

\begin{tabular}{lllll}
\hline Sample & NR & CB/NR & CNT-CB/NR & GO-CB/NR \\
\hline Hardness/shore A & 36 & 63 & 69 & 69 \\
Stress at 100\%/MPa & 0.4 & 2.4 & 4.4 & 4.2 \\
Stress at 300\%/MPa & 0.9 & 10.1 & 13.3 & 14.8 \\
Tensile strength at failure/MPa & 12.9 & 26.2 & 27.1 & 73.8 \\
Tear strength/kN/m & 27.1 & 62.3 & 73.8 & 76.6 \\
Elongation at break/\% & 734 & 606 & 552 & 483 \\
\hline
\end{tabular}

GO with the rubber. In addition, the tear strength of CNT-CB/NR and GO-CB/NR was $17.7 \%$ and $22.6 \%$, respectively higher than that of the $\mathrm{CB} / \mathrm{NR}$ composite. This was due to the sheet-like GO and the tubular CNT efficiently postponing the expansion of the tear paths when the rubber samples were stretched.

\subsection{Strain-induced crystallization}

The SIC occurring in NR composites is beneficial for delaying crack propagation and extending the fatigue life. As shown in Table 3, the SIC content in CNT-CB/NR and GO-CB/NR composites was evident at 100\% strain, which was much smaller than that observed at $200 \%$ strain in the unfilled NR composites. This indicates that the variants of carbon filler used in the research facilitated the formation of SIC in NR. This is consistent with conclusions reached by Lee and Donovan [8]. Under the same strain, the levels of SIC in CNT-CB/NR and GO-CB/NR composites were much higher than that in the CB/NR composites. The enhancement may be 
Table 3

Crystallinity (\%) of NR composites.

\begin{tabular}{llll}
\hline Strain & NR & CB/NR & CNT-CB/NR \\
\hline $100 \%$ & - & 0.09 & 0.24 \\
$200 \%$ & 0.18 & 5.73 & 0.33 \\
$300 \%$ & 2.59 & 10.81 & 7.98 \\
\hline
\end{tabular}

attributed to the CNT and GO being readily aligned during stretching due to their large aspect ratios. The alignment of both CNT and GO facilitated the untangling and rearrangement of molecular chains, which assisted the crystallization of NR [38].

\subsection{Fatigue performance}

\subsubsection{Crack propagation rate}

The crack propagation rate of the composites was small at low tearing energies $\left(<800 \mathrm{~J} / \mathrm{m}^{2}\right)$ and exponentially increased at higher tearing energies $\left(>1400 \mathrm{~J} / \mathrm{m}^{2}\right.$ ). This was consistent with the conclusions of Rivlin and Thomas [39]. For NR composites, the introduction of fillers possessing uniform geometries effectively reduced crack propagation rates owing to the structures of the filler network, especially at high tearing energies. When the tearing energy exceeded $800 \mathrm{~J} / \mathrm{m}^{2}$, the introduction of either GO or CNT significantly reduced crack propagation rates of $\mathrm{CB} / \mathrm{NR}$ composites. GO-CB/NR composites exhibited the lowest crack propagation rates among the three composites. This is mainly because the fibrous CNT and flaky GO structure facilitated the formation of complex filler networks absorbing more external energy during cyclic loading.

Furthermore, exponential equations for crack propagation rate prediction, relating crack propagation rates $(d C / d N)$ to tearing energy $(T)$ for NR composites, were derived as follows:

$$
f\left(\frac{d C}{d N}\right)=A e^{\left(-T / t_{1}\right)}+B e^{\left(-T / t_{2}\right)}+C e^{\left(-T / t_{3}\right)}+E
$$

where $A, B, C, E, t_{1}, t_{2}$ and $t_{3}$ are constant parameters related to the experimental results, shown in Table S3. In Fig. 7 the R square value for $\mathrm{CB} / \mathrm{NR}$, CNT-CB/NR and GO-CB/NR composites were $0.97,0.97$ and 0.95 respectively. In order to compare experimental results with the theoretical model, the fitting results were listed in Table 4. The values of crack propagation rate from the experimental results were close to those from the fitting results, indicating that the exponential model can be used to predict the crack growth rate of NR composites under different tearing energies.

\subsubsection{Crack tip evolution}

The crack tips of the rubber composites included peeling, breaking, passivation, branching, deflection, and sharpening. The shapes of crack tips were recorded at different fatigue cycles and shown in Fig. 8. It was found that during crack propagation the crack tips exhibited different morphologies when the composites had fillers with different geometries [40]. Fig. 8a showed an almost linear crack path for the $\mathrm{CB} / \mathrm{NR}$ composite, revealing that crack tips could go around CB particles easily and continue to progress forward in most cases. Fig. $8 \mathrm{~b}$ and $\mathrm{c}$ showed more complex crack paths for CNT-CB/NR and GO-CB/NR composites, owing to the difficulty that crack tips experienced in rounding the fibrous CNT and flaky GO structures and ultimately being arrested. The occurrence of complex crack paths further decreased the stress concentration around the original crack tips. Several secondary cracks

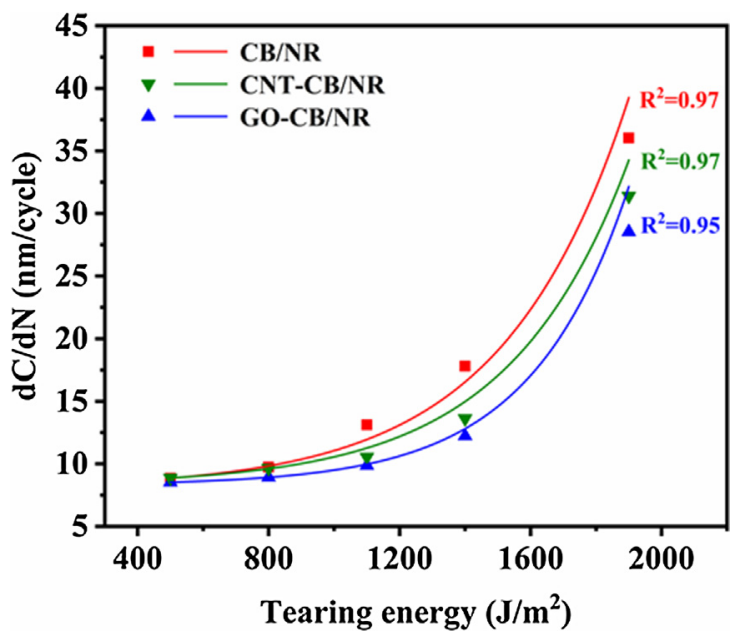

Fig. 7. Crack propagation rates of $\mathrm{CB} / \mathrm{NR}, \mathrm{CNT}-\mathrm{CB} / \mathrm{NR}$ and $\mathrm{GO}-\mathrm{CB} / \mathrm{NR}$ composites under different tearing energies. 
Table 4

Values of $\alpha_{1}$ and $\alpha_{2}$ for the composites.

\begin{tabular}{llll}
\hline Composites & $\alpha_{1}\left(\mathrm{~mm}^{2} / \mathrm{N}\right)$ & $\alpha_{2}$ & $\mathrm{R}^{2}$ \\
\hline CB/NR & $-3.31 \pm 0.29$ & $16.40 \pm 0.84$ & 0.97 \\
CNT-CB/NR & $-2.78 \pm 0.27$ & $15.35 \pm 0.83$ & 0.96 \\
GO-CB/NR & $-2.31 \pm 0.14$ & $14.44 \pm 0.47$ & 0.98 \\
\hline
\end{tabular}

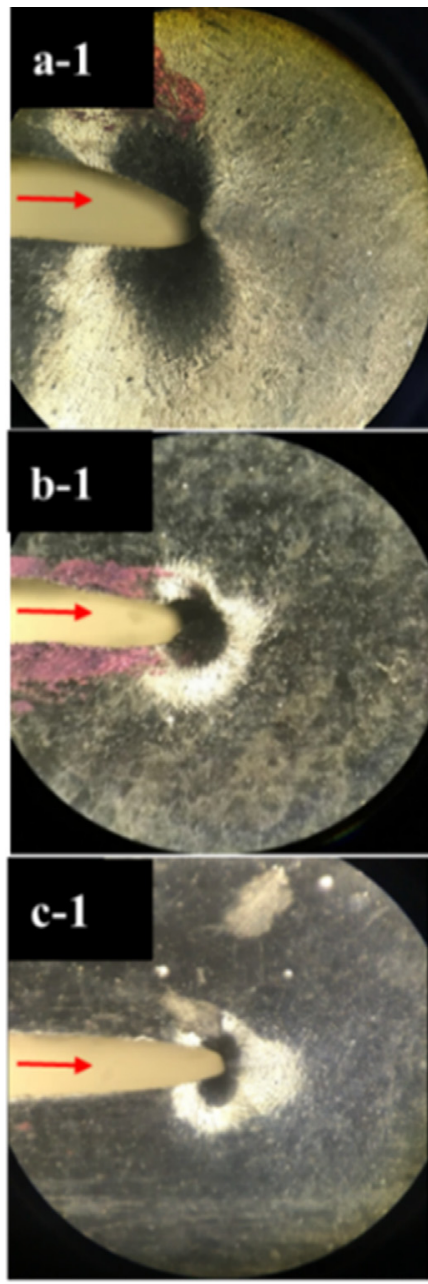

2000 Cycles

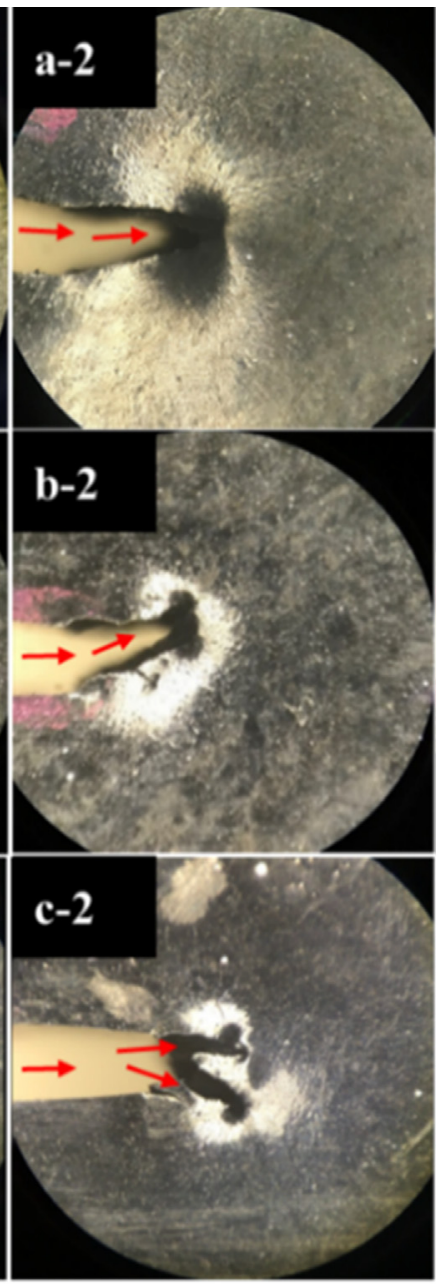

300000 Cycles

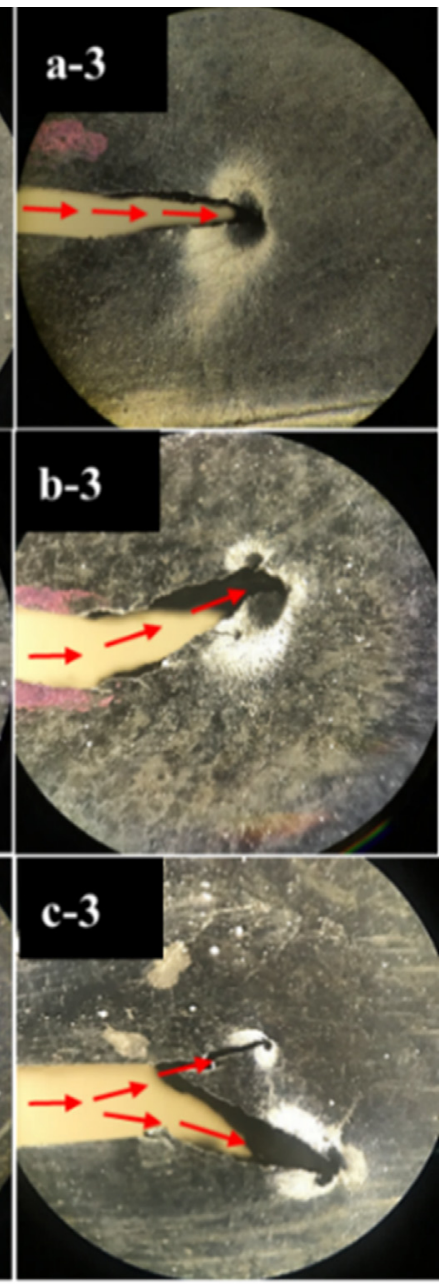

500000 Cycles

Fig. 8. Crack propagation paths of (a) CB/NR (b) CNT-CB/NR (c) GO-CB/NR composites under different fatigue cycles at $T=1.5 \mathrm{~kJ} / \mathrm{m}^{2}$.

competed with the main cracks and dispersed the tearing energy, thus reducing the crack growth rates of the composites. Therefore, the complex crack paths contributed to reducing crack propagation rates and thereby prolonged fatigue lives [40].

\subsubsection{Fatigue life}

S-N (Whöler) curves are often used to characterize the durability of composites. As shown in Fig. 9, the fatigue lives of GO-CB/NR and CNT-CB/NR composites were greater than those of CB/NR composites under the same strain. The GO-CB/NR composites exhibited the longest fatigue lives among the three composites. For instance, the fatigue life of CNT-CB/NR and GO-CB/NR composites was extended by $11.1 \%$ and $40.7 \%$, respectively, compared to those of CB/NR composites at $150 \%$ strain. The increased fatigue lives of CNT-CB/NR and GO-CB/NR composites were mainly attributed to enhanced complex filler networks and stronger interactions between both CNT and GO with the rubber molecules. In addition, the increased SIC levels in CNT-CB/NR and GO-CB/NR composites shown in Table 3 contributed to the extended fatigue lives $[3,41]$.

In order to obtain fatigue lives that mirrored conditions experienced by complexly loaded components, multi-axial cyclic testing was employed. The maximum and minimum engineering stresses were set between 5 and $9 \mathrm{MPa}$ and $0 \mathrm{MPa}$, respectively. The 


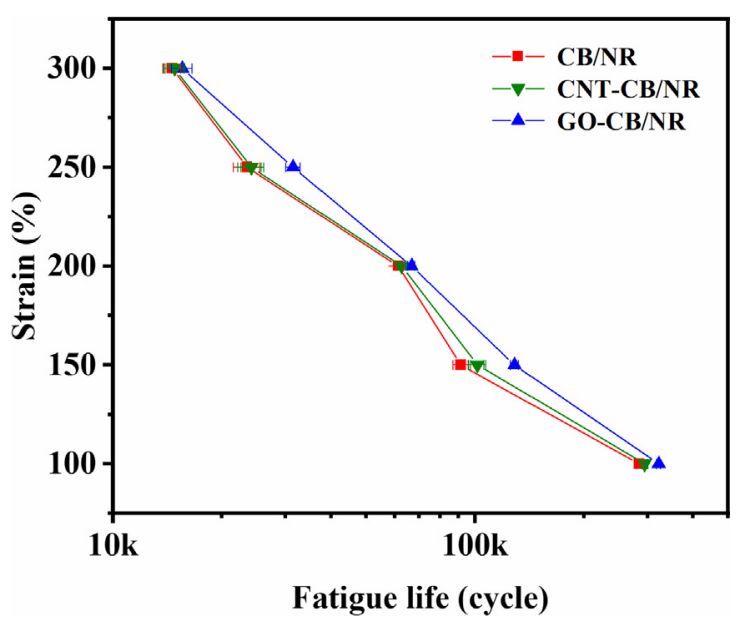

Fig. 9. S-N curves of $\mathrm{CB} / \mathrm{NR}, \mathrm{CNT}-\mathrm{CB} / \mathrm{NR}$ and GO-CB/NR composites under uniaxial cyclic loading.

experimental data and fitting data of $\mathrm{CB} / \mathrm{NR}, \mathrm{CNT}-\mathrm{CB} / \mathrm{NR}$ and GO-CB/NR composites are shown in Fig. S1. Additionally, the fitting curves of the experimental results are shown in Fig. 10. Just like other engineering materials, the fatigue lives of the composites decreased with increases in maximum engineering stress from a zero minimum stress. During fatigue cycles, the increased maximum engineering strains resulted in larger strain amplitudes and greater hysteresis with consequent heat build-up in the rubber composites. In this situation, filler networks are subject to progressive damage and fatigue lives fall. Under the same maximum engineering stress, the fatigue lives of GO-CB/NR and CNT-CB/NR were longer than those of the CB/NR composites. The GO-CB/NR composites exhibited the longest fatigue lives among the three composites. This was consistent with the results obtained for cyclic uniaxial testing. The higher fatigue lives for both GO and CNT reinforced NR-CB composites were due to them having a stronger interaction with rubber molecules when compared with NR-CB composites. The complex filler networks were more stable during cyclic loading, further reducing the likelihood of cracks being generated by the breakage of rubber molecular chains. Moreover, weak interfaces between fillers and rubber matrices were less probable. In addition, the synergistic effect between both GO and CNT and CB could effectively hinder crack propagation, which is highlighted in Fig. 7.

Based on the results from cyclic testing, an equation for fatigue life prediction using maximum engineering stress ( $\sigma$ ) can be postulated as follows [42].

$$
\ln N_{\mathrm{f}}=\alpha_{1} \sigma_{\mathrm{Max}}+\alpha_{2}
$$

where $\alpha_{1}$ and $\alpha_{2}$ were material specific constants dependent on the filler type. The values of $\alpha_{1}$ and $\alpha_{2}$ for NR composites with different fillers were shown in Table $4 . \mathrm{R}^{2}$ is commonly interpreted as the proportion of the variance in the dependent variable that is predictable from the independent variable. An $\mathrm{R}^{2}$ of 1 means the dependent variable can be predicted without error from the independent variable [35]. Table 4 shows the $\mathrm{R}^{2}$ values in the work are close to 1 , and Fig. S1 shows that experimental results were close to the fitting results. These indicated that maximum engineering stress was an effective predictor of fatigue life for these materials. Hence, the fitted curves can be used to predict the fatigue life of these rubber compounds. Additionally, the slopes of the

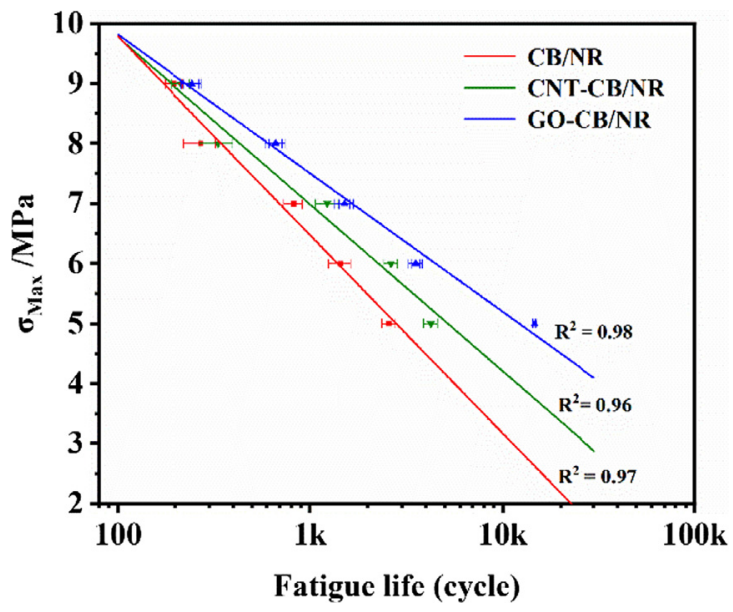

Fig. 10. Relationship between the maximum stress $\left(\sigma_{\mathrm{Max}}\right)$ and fatigue lives of the composites. 

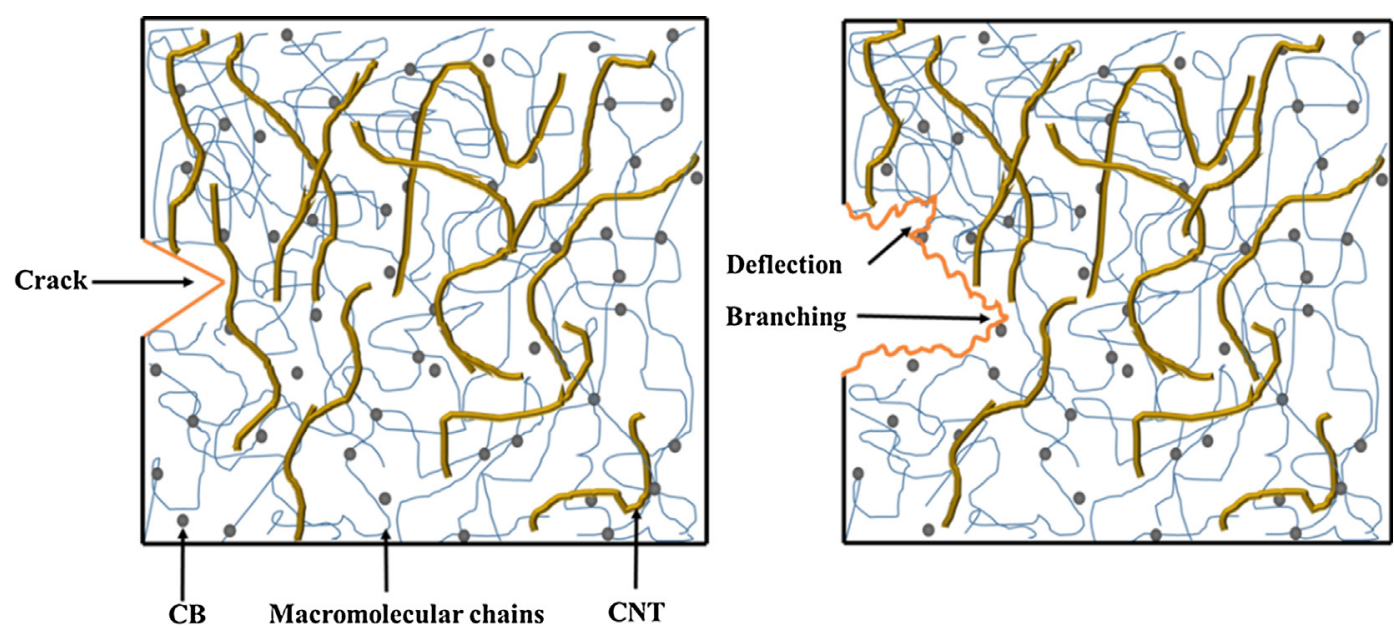

Fig. 11. Diagrammatic representation of the relation between fatigue lives and microstructures of the composites.

curves indicate the rate at which the fatigue life of each compound declined. The GO-CB/NR plot had the least pronounced gradient among the three composites, showing that the GO-CB/NR composite exhibited the highest fatigue resilience and confirmed that this material had the greatest durability.

Considering the results, it is clear that the introduction of a small amount of either GO or CNT (3 phr) significantly improved the mechanical properties and fatigue resistance of $\mathrm{CB} / \mathrm{NR}$ composites. The predominant mechanism for CNT is shown diagrammatically in Fig. 11.

The filler dispersion was observed to be more uniform after the addition of CNT or GO which was consequently beneficial in reducing stress concentration. The filler networks formed by GO-CB or CNT-CB can be visualized as a "checkerboard". During the fatigue process, the fillers dispersed gradually and with greater uniformity than in the $\mathrm{CB} / \mathrm{NR}$ composites before entering the final breakage stage [31]. This aided the reduction in stress concentration and hindered the propagation of large microcracks, thereby improving the fatigue life of the composites. Both the large sheet structure of GO or the high aspect ratios of CNT led to a stronger interaction with the rubber molecules when compared with the spherical CB particles. This strong interaction further induced high internal friction and hysteresis during cyclic loading, which was beneficial for dissipating tearing energy and decreased the crack propagation rates. The flaky GO and fibrous CNT led to the easy inducement of passivation branching and deflection of the microcrack tips during the crack expansion phase. Thereby the crack propagation rate was lessened, and fatigue lives were prolonged. Also, the high levels of SIC in GO-CB/NR and CNT-CB/NR composites contributed to crack tip passivation and facilitated longer fatigue lives $[6,8,38]$.

\section{Conclusions}

In this research, fibrous CNT and flaky GO were introduced into CB/NR composites. The CNT and GO additives were interspersed between the small CB particles, effectively reducing the CB agglomerations and forming new enhanced filler networks. The strong interfacial interaction, which formed between $\mathrm{CB}$ particles and both the GO and CNT particles, was beneficial in increasing internal friction and hysteresis loss. High levels of SIC in GO-CB/NR and CNT-CB/NR composites were also obtained. The mechanical properties of $\mathrm{CB} / \mathrm{NR}$ were improved after the introduction of either $\mathrm{GO}$ or $\mathrm{CNT}$. The fatigue tests showed that the crack propagation rates of GO-CB/NR and CNT-CB/NR were significantly lower than that of CB/NR composite. The crack tips of GO-CB/NR and CNT$\mathrm{CB} / \mathrm{NR}$ composites exhibited branched and deflected morphologies during the crack propagation phase. The fatigue lives of GO-CB/ $\mathrm{NR}$ and CNT-CB/NR composites under uniaxial and multi-axial cyclic loading were both significantly higher than that of the CB/NR composite. Especially, the GO-CB/NR composites exhibited evident advantages on mechanical properties and the fatigue resistance among the three composites.

\section{Declaration of Competing Interest}

The authors certify that there is no conflict of interest with any individual/organization for the present work.

\section{Acknowledgements}

We gratefully acknowledge financial support from the National Key R\&D Program of China (2017YFE0126800) and the National Natural Science Foundation of China (51573007). 


\section{Appendix A. Supplementary material}

Supplementary data to this article can be found online at https://doi.org/10.1016/j.engfracmech.2019.106764.

\section{References}

[1] Ruellan B, Le Cam J-B, Robin E, Jeanneau I, Canévet F, Mauvoisin G, et al. Fatigue crack growth in natural rubber: the role of SIC investigated through postmortem analysis of fatigue striations. Eng Frac Mech 2018;201:353-65. https://doi.org/10.1016/j.engfracmech.2018.07.001.

[2] Rublon P, Huneau B, Verron E, Saintier N, Beurrot S, Leygue A, et al. Multiaxial deformation and strain-induced crystallization around a fatigue crack in natural rubber. Eng Frac Mech 2014;123:59-69. https://doi.org/10.1016/j.engfracmech.2014.04.003.

[3] Saintier N, Cailletaud G, Piques R. Cyclic loadings and crystallization of natural rubber: an explanation of fatigue crack propagation reinforcement under a positive loading ratio. Mater Sci Eng, A -Struct 2011;A528(3):1078-86. https://doi.org/10.1016/j.msea.2010.09.079.

[4] Cha JH, Shin G-J, Kang M-J, Lee HI, Rhee KY, Park S-J. A study on the effect of electron acceptor-donor interactions on the mechanical and interfacial properties of carbon black/natural rubber composites. Compos Part B-Eng 2018;136:143-8. https://doi.org/10.1016/j.compositesb.2017.10.003.

[5] Adhikari B, Ghosh AK, Maiti S. Developments in carbon black for rubber reinforcement. J Polym Mater 2000;17(2):101-25.

[6] Trabelsi S, Albouy PA, Rault J. Stress-induced crystallization around a crack tip in natural rubber. Macromolecules 2002;35(27):10054-61. https://doi.org/10. $1021 / \mathrm{ma0} 21106 \mathrm{c}$.

[7] Stacer RG, Yanyo LC, Kelley FN. Observations on the tearing of elastomers. Rubber Chem Technol 1985;58(2):421-35. https://doi.org/10.5254/1.3536075.

[8] Lee DJ, Donovan JA. Microstructural changes in the crack tip region of carbon black-filled natural rubber. Rubber Chem Technol 1987;60(5):910-23. https:// doi.org/10.5254/1.3536164.

[9] Hamed GR, Huang MY. Tensile and tear behavior of anisotropic double networks of a black-filled natural rubber vulcanizate. Rubber Chem Technol 1998;71(5):846-60. https://doi.org/10.5254/1.3538513.

[10] Hamed GR, Zhao J. Longitudinal cracking in a carbon black-filled natural rubber vulcanizate during chemical stress relaxation. Rubber Chem Technol 1998;71(2):157-67. https://doi.org/10.5254/1.3538477.

[11] Hamed GR, Zhao J. Tensile behavior after oxidative aging of gum and black-filled vulcanizates of SBR and NR. Rubber Chem Technol 1999;72(4):721-30. https://doi.org/10.5254/1.3538829.

[12] Hamed GR, Rattanasom N. Effect of crosslink density on cut growth in black-filled natural rubber vulcanizates. Rubber Chem Technol 2002;75(5):935-41. https://doi.org/10.5254/1.3547693.

[13] Hamed GR, Al-Sheneper AA. Effect of carbon black concentration on cut growth in NR vulcanizates. Rubber Chem Technol 2003;76(2):436-59. https://doi.org/ $10.5254 / 1.3547753$.

[14] Cao L, Sinha TK, Tao L, Li H, Zong C, Kim JK. Synergistic reinforcement of silanized silica-graphene oxide hybrid in natural rubber for tire-tread fabrication: a latex based facile approach. Compos Part B-Eng 2019;161:667-76. https://doi.org/10.1016/j.compositesb.2019.01.024.

[15] Li F, Liu J, Mars WV, Chan TW, Lu Y, Yang H, et al. Crack precursor size for natural rubber inferred from relaxing and non-relaxing fatigue experiments. Int J Fatigue 2015;80:50-7. https://doi.org/10.1016/j.ijfatigue.2015.05.011.

[16] Sharika T, Abraham Jiji, Arif P Mohammad, George Soney C, Kalarikkal Nandakumar, Thomas Sabu. Excellent electromagnetic shield derived from MWCNT reinforced NR/PP blend nanocomposites with tailored microstructural properties. Compos B Engng 2019;173:106798. https://doi.org/10.1016/j. compositesb:2019.05.009.

[17] Kang I, Heung YY, Kim JH, Lee JW, Gollapudi R, Subramaniam S, et al. Introduction to carbon nanotube and nanofiber smart materials. Compos Part B-Eng 2006;37B(6):382-94. https://doi.org/10.1016/j.compositesb.2006.02.011.

[18] Doll K, Ural A. Mechanical evaluation of hydroxyapatite nanocomposites using finite element modeling. J Eng Mater Tech 2013;135(1):011007https://doi.org/ $10.1115 / 1.4023187$.

[19] Ji XY, Cao YP, Feng XQ. Micromechanics prediction of the effective elastic moduli of graphene sheet-reinforced polymer nanocomposites. Modell Simul Mater Sci Eng 2010;18(4):45005. https://doi.org/10.1088/0965-0393/18/4/045005.

[20] Acar A, Colak O, Correia JPM, Ahzi S. Cooperative-VBO model for polymer/graphene nanocomposites. Mech Mater 2018;125:1-13. https://doi.org/10.1016/j. mechmat.2018.06.005.

[21] Lu Y, Liu J, Hou G, Ma J, Wang W, Wei F, et al. From nano to giant? designing carbon nanotubes for rubber reinforcement and their applications for high performance tires. Compos Sci Technol 2016;137:94-101. https://doi.org/10.1016/j.compscitech.2016.10.020.

[22] Liu S, Tian M, Zhang L, Lu Y, Chan TW, Ning N. Tailoring dielectric properties of polymer composites by controlling alignment of carbon nanotubes. J Mater Sci 2016;51(5):2616-26. https://doi.org/10.1007/s10853-015-9575-y.

[23] Katihabwa A, Wang W, Jiang Y, Zhao X, Lu Y, Zhang L. Multi-walled carbon nanotubes/silicone rubber nanocomposites prepared by high shear mechanical mixing. J Reinf Plast Comp 2011;30(12):1007-14. https://doi.org/10.1177/0731684410394008.

[24] Amnuaypornsri S, Sakdapipanich J, Toki S, Hsiao BS, Ichikawa N, Tanaka Y. Strain-induced crystallization of natural rubber: effect of proteins and phospholipids. Rubber Chem Technol 2008;81(5):753-66. https://doi.org/10.5254/1.3548230.

[25] Li X, Zhu Y, Cai W, Borysiak M, Han B, Chen D, et al. Transfer of large-area graphene films for high-performance transparent conductive electrodes. Nano Lett 2009;9(12):4359-63. https://doi.org/10.1021/n1902623y.

[26] Krishnamoorthy K, Veerapandian M, Yun K, Kim SJ. The chemical and structural analysis of graphene oxide with different degrees of oxidation. Carbon 2013;53:38-49. https://doi.org/10.1016/j.carbon.2012.10.013.

[27] Su C-Y, Xu Y, Zhang W, Zhao J, Tang X, Tsai C-H, et al. Electrical and spectroscopic characterizations of ultra-large reduced graphene oxide monolayers. Chem Mater 2009;21(23):5674-80. https://doi.org/10.1021/cm902182y.

[28] Zhao G, Li J, Ren X, Chen C, Wang X. Few-layered graphene oxide nanosheets as superior sorbents for heavy metal ion, water pollution control. Environ Sci Technol 2011;45(24):10454-62. https://doi.org/10.1021/es203439v.

[29] Bai X, Zhai Y, Zhang Y. Green approach to prepare graphene-based composites with high microwave absorption capacity. J Phys Chem C 2011;115(23):11673-7. https://doi.org/10.1021/jp202475m.

[30] Hirata M, Gotou T, Horiuchi S, Fujiwara M, Ohba M. Thin-film particles of graphite oxide 1: high-yield synthesis and flexibility of the particles. Carbon 2004;42(14):2929-37. https://doi.org/10.1016/S0008-6223(04)00444-0.

[31] Zhang S, Zheng L, Liu D, Xu Z, Zhang L, Liu L, et al. Improved mechanical and fatigue properties of graphene oxide/silica/SBR composites. RSC Adv 2017;7(65):40813-8. https://doi.org/10.1039/C7RA06635J.

[32] Villmow T, Pötschke P, Pegel S, Häussler L, Kretzschmar B. Influence of twin-screw extrusion conditions on the dispersion of multi-walled carbon nanotubes in a poly(lactic acid) matrix. Polymer 2008;49(16):3500-9. https://doi.org/10.1016/j.polymer.2008.06.010.

[33] Amstutz C, Bürgi M, Jousset P. Characterisation and FE simulation of polyurethane elastic bonded joints under multiaxial loading conditions. Int J Adhes Adhes 2018;83:103-15. https://doi.org/10.1016/j.ijadhadh.2018.02.029.

[34] Zhou Y, Jerrams S, Betts A, Chen L. Fatigue life prediction of magnetorheological elastomers subjected to dynamic equi-biaxial cyclic loading. Mater Chem Phys 2014;146(3):487-92. https://doi.org/10.1016/j.matchemphys.2014.03.059.

[35] Zhou Y, Jerrams S, Betts A, Farrell G, Chen L. The influence of particle content on the equi-biaxial fatigue behaviour of magnetorheological elastomers. Mater Des 2015;67:398-404. https://doi.org/10.1016/j.matdes.2014.11.056.

[36] Le Cam J-B, Huneau B, Verron E. Fatigue damage in carbon black filled natural rubber under uni- and multiaxial loading conditions. Int J Fatigue 2013;52:82-94. https://doi.org/10.1016/j.ijfatigue.2013.02.022. 
[37] Le Cam JB, Huneau B, Verron E, Gornet L. Mechanism of fatigue crack growth in carbon black filled natural rubber. Macromolecules 2004;37(13):5011-7. https://doi.org/10.1021/ma0495386.

[38] Nie Y, Wang B, Huang G, Qu L, Zhang P, Weng G, et al. Relationship between the material properties and fatigue crack-growth characteristics of natural rubber filled with different carbon blacks. J Appl Polym Sci 2010;117(6):3441-7. https://doi.org/10.1002/app.32098,

[39] Rivlin RS, Thomas AG. The incipient characteristic tearing energy for an elastomer crosslinked under strain. J Polym Sci, Polym Phys 1983;21(9):1807-14. https://doi.org/10.1002/pol.1983.180210916.

[40] Weng G, Yao H, Chang A, Fu K, Liu Y, Chen Z. Crack growth mechanism of natural rubber under fatigue loading studied by a real-time crack tip morphology monitoring method. RSC Adv 2014;4(83):43942-50. https://doi.org/10.1039/C4RA06518B.

[41] Santangelo PG, Roland CM. Role of strain crystallization in the fatigue resistance of double network elastomers. Rubber Chem Technol 2003;76(4):892-8. https://doi.org/10.5254/1.3547779.

[42] Zhou Y, Jiang L, Chen S, Ma J, Betts A, Jerrams S. Determination of reliable fatigue life predictors for magnetorheological elastomers under dynamic equi-biaxial loading. Poly Test 2017;61:177-84. https://doi.org/10.1016/j.polymertesting.2017.05.021. 